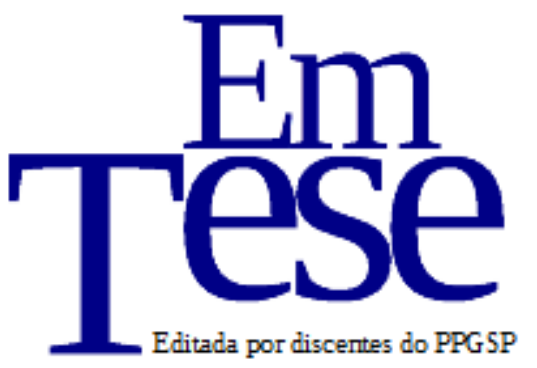

UFSC

PPG SP PROG RAMA DE

PÓS-GRADUAÇÃO EM

Sociologia

Política

v. 14, n. 1, jan./jun., 2017

\title{
Educação e conhecimento político: duas faces de uma mesma moeda ou moedas diferentes?
}

\author{
Robert Lee Vidigal ${ }^{1}$ \\ Álvaro João Pereira Filho
}

\begin{abstract}
Resumo: O papel da educação formal na sofisticação política dos indivíduos é alvo de amplo debate. Entretanto, a educação, principalmente o ensino superior, fornece ferramentas para o entendimento sobre política, socializa valores cívicos e cria contatos sociais importantes para o acesso à informação, que são essenciais para a construção de um cidadão sofisticado. Utilizandose do ESEB 2010 e 2014, avaliamos tanto a existência de efeito de cada grau de educação formal sobre o conhecimento factual de assuntos políticos. A partir dos resultados, afirmamos que a escolaridade não deve ser tratada de forma linear, já que o ensino superior aparece como divisor de águas na naturalização do mundo político, e, portanto, educação deve ser tratada através de categorias dicotômicas que represente cada grau educacional.
\end{abstract}

Palavras-chave: Educação. Conhecimento político. Democracia. Ensino Superior.

\section{Education and political knowledge: two sides of the same coin or different currencies?}

\begin{abstract}
The role of formal education in political sophistication of individuals is subject to wide discussion. However, education, especially higher education, provides tools for understanding politics, socializes civic values and creates important social contacts for access to information, which are essential for building a sophisticated citizen. Using the ESEB 2010 and 2014, we evaluated both the existence of effect of each degree of formal education on factual knowledge of political affairs. The results show that education should not be treated in a linear fashion, as the higher education appears as a watershed in the naturalization of the political world, and therefore education should be treated through dichotomous categories representing each educational grade.
\end{abstract}

Keywords: Education, Political Knowledge, Democracy, Higher Education.

\footnotetext{
${ }^{1}$ Mestre em Ciência Política pela Universidade de Brasília (UnB). E-mail: robertleehc@ gmail.com.

${ }^{2}$ Mestre em Ciência Política pela Universidade de Brasília (UnB). E-mail: alvarojp@gmail.com.
} 


\section{Introdução}

Uma premissa básica para um bom sistema democrático é que os cidadãos sejam capazes de utilizar as informações sobre política para regular, responsabilizar e avaliar os seus representantes. Entretanto, algumas pessoas sabem e pensam mais sobre política do que outras. Essa diferença torna os indivíduos mais informados detentores de um recurso valioso e o sistema educacional é visto como uma importante fonte de capacitação do eleitorado de um país.

A educação formal é um meio eficiente de transmissão de conhecimentos e de desenvolvimento das habilidades cognitivas necessárias para as estruturas que implicam no conhecimento político (ALTHAUS, 1998). O debate em torno do papel da educação se iniciou a partir de estudos que apresentaram resultados divergentes, tanto em relação à significância quanto ao tamanho de efeito. Em alguns trabalhos (LUSKIN, 1990; HIGHTON, 2009) essa variável possui um efeito fraco, sendo apenas uma proxy para o efeito de outras. Já para outros autores, a educação aparece como o melhor preditor do conhecimento político (DELLI CARPINI e KEETER, 1996). Portanto, o presente trabalho avalia o efeito da educação no conhecimento político. A partir de modelos multivariados de regressão e dos dados do Estudo Eleitoral Brasileiro (ESEB) de 2014 e 2010, buscamos responder: qual é o papel da educação formal na explicação do conhecimento político? Ou seja, quanto a educação contribui para o indivíduo saber ou não sobre política? E, finalmente, qual é o ganho informacional de cada grau de escolaridade para o conhecimento político?

A educação influenciaria o conhecimento político por meio de seus efeitos sobre os caminhos sociais e carreiras que, posteriormente, levam as pessoas à ambientes que facilitam o desenvolvimento, manutenção e armazenamento de informação política (HIGHTON, 2009).

Toda educação, mas sobretudo educação superior, tem um forte efeito no conhecimento político através do desenvolvimento de habilidades e orientações individuais que tornam mais fácil compreender e armazenar a informação política (DELLI CARPINI; KEETER, 1996, p. 192-93).

A educação gera um efeito informacional: aulas, discussões informais, leituras e exposição à informação. Os temas políticos, principalmente no ensino superior, se tornam parte do cotidiano do indivíduo por meio de leituras, convívio social e o próprio voto. Assim, apesar de educação possuir um efeito positivo sobre o conhecimento do eleitorado, argumentamos que o ensino superior é o grau com os maiores ganhos nos níveis de conhecimento político, pois as informações sobre política passam a ser mais complexas e em maior quantidade.

Logo, os diferentes graus de educação não representam um ganho homogêneo de 
informação, isto é, os ganhos de conhecimento entre os níveis educacionais não são semelhantes. Consequentemente, não se pode tratar educação de forma linear devido as diferenças qualitativas e quantitativas de cada grau de ensino. Assim, educação deve ser utilizada em modelos de regressão em suas devidas categorias dicotômicas.

\section{Democracia e sofisticação política}

A qualidade da democracia é uma das principais preocupações da ciência política e um grande dilema está presente nesse regime: como exigir uma participação universal e qualificada dos seus cidadãos, uma vez que alguns simplesmente não querem participar ou não se interessam. Para que os governos possam garantir direitos e estabelecer deveres, os seus cidadãos devem conhecer quais são os principais aspectos que compõem um regime democrático (DELLI CARPINI e KEETER, 1996).

O debate sobre o papel da cidadania não é recente. Em Atenas, os cidadãos participavam diretamente na vida pública, seja legislando ou exercendo funções públicas. Os indivíduos eram orientados para o coletivo e para a composição da esfera pública. Devido à diferença "natural" entre os indivíduos, a autoridade máxima era restrita aos reis filósofos, segundo Platão, por conta da grande capacidade destes em relação ao resto da sociedade. Por outro lado, Aristóteles defendia que a autoridade residiria na população como um todo, porém a democracia seria algo ruim e indesejado, pois tenderia ao governo de poucos e tiranos.

O conceito de cidadania sofreria grande mudança com os contratualistas. Em Locke, as diferenças entre os cidadãos seriam dadas pela capacidade de produção do seu próprio trabalho e das suas habilidades, e não por naturezas políticas. Logo, o Estado passaria a se orientar para a proteção dos indivíduos e do fruto de seus trabalhos, uma clara reação ao absolutismo. Mas, alguns cidadãos seriam mais capazes de exercer funções públicas e variariam na quantidade de informação política que poderia ser adquirida, segundo sua capacidade de realizar trabalho.

Por outro lado, Rousseau resgata a necessidade do cidadão participar da esfera pública, porque essa possui um caráter educativo. As instituições deveriam promover a participação direta e os cidadãos serem "forçados" a participar, promovendo os valores da comunidade e a verdadeira liberdade individual. Esse argumento foi inserido dentro da constituição norteamericana e na aplicação de ensino cívico nas escolas daquele país (DELLI CARPINI e KEETER, 1996), porém limitando a participação dos cidadãos ao direito de voto.

Em Converse (1964), há a retomada importante do argumento clássico da diferença de conhecimento entre o público de massa e a elite política, com a necessidade de sistemas de crenças mais coerentes e estáveis para o uso da ideologia no posicionamento sobre temas 
políticos (BENNETT, 2006). Esses sistemas são configurações cognitivas de ideias e atitudes aglomeradas por inter-relações funcionais ou probabilísticas. As diferenças entre os sistemas acontecem parcialmente pela educação do indivíduo, e também por gostos e interesses desenvolvidos ao longo do tempo (BENNETT, 2006).

A disposição cognitiva dos sistemas de crenças varia entre os indivíduos de diferentes maneiras (CONVERSE, 1964), segundo sua: (i) centralidade; (ii) probabilidade das relações entre as atitudes; (iii) estabilidade das ideias; (iv) e pela quantidade de informação para construção das atitudes. Dessa maneira, a elite política possuiria sistemas com configurações que permitiriam conexões entre ideias e atitudes, acesso aos conhecimentos mais abstratos, como o conteúdo político, e o entendimento de fenômenos sociais (CONVERSE, 1964). Por outro lado, o público de massa um momento possui opiniões genuínas e não abre mão delas, em outro é indiferente ou apenas não possui atitudes e crenças significativas.

$\mathrm{Na}$ busca de replicar os achados de Converse, alguns trabalhos encontraram inconsistência quanto ao uso da ideologia (NIE e ANDERSEN, 1974; BENNETT, 2006) e ao interesse em política (NEUMAN, 1986; BENNETT, 2006), e assim, dando pouca atenção ao contexto político ao longo do tempo (KINDER, 2006). Todavia, cada vez mais novos estudos foram feitos elaborando e trazendo o papel da sofisticação política para o centro das discussões da competência democrática, colocando essa expertise como uma variável essencial para os estudos de comportamento político (LUSKIN, 1990; ZALLER, 1992; DELLI CARPINI e KEETER, 1996).

Assim, sofisticação se tornou, para parte da ciência política, um fator crítico para o exercício da cidadania em democracias representativas (DELLI CARPINI e KEETER, 1996), pois permite ao cidadão identificar seus interesses, deliberar e participar da política para além das urnas. A sofisticação política se refere à amplitude, profundidade e organização das cognições políticas de uma pessoa (LUSKIN, 1990). Quando sofisticados, os cidadãos tendem a ter crenças bem definidas e são mais propensos a expressar as preferências consistentes com suas predisposições (ZALLER, 1992). São eles que mais se aproximam de um "voto correto" 3 (LAU e REDLAWSK, 2006; LAU, ANDERSEN e REDLAWSK, 2008). Ainda, os sofisticados seriam mais tolerantes (ERIKSON e TEDIN, 2011) e participativos (HIGHTON, 2009; DINESEN et. al., 2016), o que é alinhado com as expectativas e os valores democráticos amplamente difundidos.

Porém, a população não é homogênea quanto a sua capacidade de exercer sua cidadania. O que, o quanto e como as pessoas sabem sobre política, portanto, é efeito de atributos tanto individuais, quanto contextuais (DELLI CARPINI e KEETER, 1996;

\footnotetext{
${ }^{3}$ Voto correto, segundo Richard Lau e David Redlawsk (2006) é o voto de um indivíduo completamente informado sobre esse voto. Caso o cidadão recebe todas as informações sobre um candidato e ainda permanecer declarando o voto a esse, mede-se, portanto, esse voto como o "correto".
} 
LUSKIN, 1990; BARABAS et al., 2014), não se limitando às características inatas de uma parte da população, como teorias clássicas desenhavam. Estão presentes nos atributos individuais, a habilidade e a motivação que influenciam na capacidade de entender e lidar com a política.

No atributo contextual, a oportunidade surge como importante fator, que reflete as características dos grupos e a suas trajetórias históricas na política, tornando desigual na sociedade o acesso ao conteúdo político. Assim, para se tornar uma pessoa altamente informada não basta ser apenas brilhante e capaz de acumular as informações adequadas sobre política, é necessário estar exposto à informação, de forma que ela chegue ao receptor (BARTELS, 1996), da mesma forma que haja interesse suficiente de armazenar e processar tal tipo de informação.

Especificamente, a oportunidade diz respeito à disponibilidade de informação política, por exemplo, a ocupação de determinados cargos e, o pertencimento a determinados grupos sociais. Determinados grupos possuem diferentes oportunidades que afetam a distribuição da sofisticação política, dependendo de sua trajetória histórica. Um exemplo clássico é a diferença entre homens e mulheres. Mulheres foram excluídas das discussões políticas e do sufrágio por décadas, o que gerou um déficit de sofisticação em relação aos homens, assim como os negros em relações aos brancos (RENNÓ, 2007).

Já a motivação é o desejo interno de aprender sobre política, que chamamos de interesse (LUSKIN, 1990). Ao longo da vida, o interesse varia, assim como o acesso a determinados meios de comunicação, e por consequência, a busca de novas informações. Pessoas com maior interesse em política buscam mais informações e, assim, possuem maior sofisticação (LUSKIN, 1990; BARABAS et. al., 2014). Da mesma forma, pessoas com pouco interesse em política ficam alheias aos fatos e aos ocupantes dos cargos que formam o sistema político e participando pouco da política (KINDER, 1998).

Por fim, a habilidade se refere à capacidade cognitiva de organizar e armazenar as informações e reconhecer aquelas que são adequadas. Esse fator possui tanto características do próprio indivíduo desde os seus primeiros anos, até o desenvolvimento e treinamento em meios políticos, como partidos, ou com a própria educação formal, com o ensino cívico e a apresentação de aspectos básicos que compõem a política local.

\section{Como educação afeta a sofisticação?}

A educação é uma das variáveis mais comuns em modelos de comportamento político. Ainda assim, sua relação com a sofisticação política dos cidadãos é debatida em vários trabalhos. Alguns, por exemplo, afirmam que a educação esconde uma série de efeitos de 
outras variáveis (LUSKIN, 1990; HIGHTON, 2009), como inteligência e outros fatores que surgem antes mesmo da entrada no sistema de educação formal, nos primeiros anos na vida de um indivíduo.

Outros acreditam que a educação formal contribuiria de forma decisiva para explicar sofisticação. Converse (1964) afirmou que a educação é o solvente universal, isto é, tem papel primordial em explicar o interesse, o conhecimento e a participação dos cidadãos na política, ou seja, as principais variáveis do comportamento. Dois efeitos importantes são promovidos pela educação: a socialização e a diferenciação. Diversas regras sociais e características da sociedade e de governo são ensinadas e difundidas para outras gerações dentro da educação formal. Regras sociais das mais básicas, como a fila, representação, autoridade e solidariedade são reproduzidas e socializadas nas escolas e colégios. Os conhecimentos sobre a esfera pública de governo e sobre seus valores democráticos seriam repassados para os alunos por fazerem parte dos instrumentos mais básicos e importantes para um cidadão.

Por outro lado, a educação também é um fator diferenciador entre os indivíduos. Sejam as consequências no mercado de trabalho e toda a ressonância que isso gera na vida de um cidadão, a educação continua sendo responsável pelo sucesso ou fracasso da carreira de um indivíduo. Há também diferenças entre as qualidades dos ensinos, variando a depender das características demográficas do indivíduo. Isso gera uma série consequências para uma infinidade de outras variáveis, que são consideradas essenciais para explicar o quanto uma $\begin{array}{lllll}\text { pessoa } & \text { sabe não } & \text { política. }\end{array}$

Esses dois efeitos incidem diretamente sobre os fatores presentes na sofisticação. A educação formal é capaz de naturalizar dentro de um cidadão o dever cívico (DINESEN et. al., 2016), aumentando o interesse e a probabilidade de participação política. Ela também permite o desenvolvimento de habilidades cognitivas importantes para o entendimento do complexo mundo político. E, por fim, cria redes sociais capazes de criar acesso à informação política e aos que fazem política, aumentando a oportunidade do indivíduo.

Portanto, espera-se que esses efeitos da educação formal sobre os fatores individuais e contextuais da sofisticação sejam diretamente proporcionais, ou seja, quanto maior o grau de escolaridade do indivíduo maior seja a sofisticação política ${ }^{4}$ (H1). Maior serão a habilidade cognitiva desenvolvida, a promoção do interesse em assuntos políticos e a oportunidade de acesso à informação política. Entretanto, não se pode esperar que essa relação seja linear $(\mathrm{H} 2)$.

Ensinos fundamentais e médios fornecem os conhecimentos contextuais sobre história,

\footnotetext{
${ }^{4}$ A sofisticação política se trata de um fenômeno cognitivo, e assim, não pode ser vista ou enumerada (Bullock, 2004). As medidas são baseadas no conhecimento factual que o indivíduo possui sobre a política. Essas medidas se tornaram padrão (e.g. DELLI CARPINI e KETTER, 1996; ALTHAUS, 1998; BULLOCK, 2004; PRIOR e LUPIA, 2008), sendo o conhecimento tratado como uma proxy para sofisticação política.
} 
geografia e outros temas que posteriormente facilitam o aprendizado sobre política. No entanto, é o ensino superior que possibilita uma visão crítica sobre o que acontece ao redor do indivíduo, permitindo uma visão mais ampla, profunda e complexa da sociedade. Uma das funções mais importantes do ensino superior é ajudar o indivíduo a desenvolver o conhecimento acadêmico necessário para ter sucesso em uma determinada carreira. Todas as carreiras exigem uma especialização em uma área, e as instituições de ensino como faculdades e universidades ajudam a construir tal habilidade. Assim, ao tratar da variação da escolaridade, o seu comportamento não é linear, pois cada grau escolar contribui de forma heterogênea, com ganhos diferentes quando se passa de um grau para o outro.

O ensino superior também oferece muitos benefícios sociais e individuais. A maioria das instituições de ensino superior oferece uma variedade de atividades extracurriculares e agremiações para os estudantes. Esses grupos ajudam a promover interações sociais, motivam debates políticos e influi na participação política. Além disso, o ensino superior promove oportunidade de interações sociais entre pessoas de diversas origens e pensamentos, como também maiores oportunidades no futuro, tais como de trabalho e salário ${ }^{5}$. Outrossim, é em média a partir dos 18 anos de idade que se entra em uma universidade no Brasil, ou seja, é a ocasião em que o voto se torna obrigatório e os indivíduos são obrigados a lidar com a política. Logo, cursar um ensino superior fornece aos indivíduos maior sofisticação política do que os alunos dos cursos secundaristas (H2).

Portanto, testamos o efeito explicativo da educação superior na sofisticação política como principal determinante para o conhecimento político dos indivíduos (H1). Sabendo que o nível de sofisticação no Brasil e no mundo é baixo, o debate em torno de como aumentar o nível de conhecimento do público, a educação formal surge como uma saída para que a população em países democráticos usufrua dos benefícios de um eleitorado altamente sofisticado. Entre diversas variáveis, a educação é uma que permite que o governo e a sociedade civil, através de políticas públicas, promovam o aumento do conhecimento político da população em geral.

\section{Dados e método}

Os dados foram extraídos do Estudo Eleitoral Brasileiro (ESEB) de 2014 e 2010, uma pesquisa pós-eleitoral de cunho político e socioeconômico, realizada em 195 municípios por todo o país e estratificada por Estado. Em 2010 e 2014, os tamanhos das amostras foram de aproximadamente de 2000 e 3100 respondentes, respectivamente.

\footnotetext{
${ }^{5}$ Pessoas com maiores salários são mais prováveis do que as demais de adquirir informação econômica e política por meio de suas atividades diárias (ALTHAUS, 1996), pois estão em altos cargos e possuem mais acesso à informação.
} 
O modelo de análise utiliza de regressão múltipla, como nos trabalhos pioneiros de Delli Carpini e Keeter (1996, capítulo 6) e Bartels (1996), com o objetivo de encontrar o efeito do ensino superior sob o conhecimento político. Dessa maneira, serão testados os diferentes graus de escolaridade, para sabermos qual o efeito de cada um sobre a sofisticação do eleitor brasileiro. Espera-se dessa variável um efeito positivo em relação à sofisticação política do eleitor.

Portanto, a sofisticação política - variável dependente do modelo - foi operacionalizada a partir de três áreas disponíveis no ESEB 2014: perguntas factuais, posicionamento de partidos e o posicionamento próprio no espectro ideológico. A primeira área é caracterizada por perguntas factuais gerais e dinâmicas (BARABAS ET. AL., 2014), ou seja, perguntas sobre a política nacional, sobre atores políticos que estão ocupando determinados cargos e sobre índices econômicos. Por exemplo, em 2010 se pergunta se o presidente da República tem um mandato de 4 anos e se os deputados da câmara federal são eleitos pelo voto majoritário, enquanto que em 2014 se pergunta quem é o secretário-geral da Organização das Nações Unidas (ONU) e a taxa de desemprego daquele ano.

A segunda e a terceira área são de posicionamento no espectro ideológico. Essas duas áreas são incluídas já que o posicionamento ideológico é uma tarefa que exige expertise por parte do entrevistado, princípios ideológicos são altamente abstratos e exigentes para a maioria da população (LUSKIN, 1990; KINDER, 2006). O posicionamento de partidos foi, primeiramente, feito para cada uma das legendas, e posteriormente dois posicionamentos relativos - Partido dos Trabalhadores (PT) e Partido da Social Democracia Brasileira (PSDB); PT e Democratas (DEM) - foram incluídos na construção da escala da variável dependente. Por exemplo, para pontuar como correto era preciso posicionar o PT mais à esquerda do que ao PSDB ou ao DEM. Por fim, a terceira área é o posicionamento pessoal. Assim como o posicionamento dos partidos exige expertise, o posicionamento pessoal também exige uma capacidade cognitiva complexa ${ }^{6}$ (LUSKIN, 1990). Algumas pessoas podem não saber se posicionar dentro do espectro, ou não saber o que significa os conceitos ideológicos de esquerda ou direita.

Infelizmente, as questões presentes nos ESEB realizados em 2010 e 2014 não são propriamente as mesmas, com algumas exceções, o que merece cautela no momento de comparação. Entretanto, em ambos anos, perguntas envolvendo as 3 áreas de conhecimento político (BARABAS et al., 2014) estão presentes. Para ter uma ideia da evolução do conhecimento político do eleitorado, construímos escalas baseadas nas três áreas do

\footnotetext{
${ }^{6} 54 \%$ (2014) e 44\% (2010) dos entrevistados não sabem (não sei/não respondeu) se posicionar ideologicamente na escala de esquerda e direita. Os números são altos, pois a posição no espectro ideológico pode, por exemplo, ser influenciada pelo simples fato de haver uma eleição, entretanto, mesmo em uma pesquisa pós-eleitoral como o ESEB, a maioria da população não sabe se posicionar ideologicamente mostra que essa tarefa exige uma maior expertise política.
} 
conhecimento politico.

O alfa de Cronbach para a escala de conhecimento político construída para 2014 é de 0.61 e para 2010 é de 0.59, valores inferiores aos relatados em Zaller (1992) e Delli Carpini e Keeter (1996), devido ao fato de que as escalas utilizadas nesses estudos incluem mais itens. Porém, isso não é problemático por duas razões: (i) a escala de conhecimento político é usada como variável dependente e a falta de confiabilidade perfeita em uma variável dependente não gera estimativas enviesadas dos parâmetros como acontece quando as variáveis independentes são medidas com erro (HIGHTON, 2009); (ii) o pressuposto de "dificuldade igual dos itens", devido à natureza das escalas de conhecimento político, não é cumprido, logo, o alfa tende a ser consequentemente baixo (ZALLER, 1992, p. 340).

No modelo são incluídas as seguintes variáveis independentes:

Educação: Educação é a principal variável no modelo. Espera-se que quanto maior o grau de escolaridade do entrevistado, maior seja seu número de respostas corretas nas perguntas de conhecimento político. Porém, seu efeito não é linear em relação à cada grau de escolaridade. Isto é, uma pessoa que completa o ensino médio não possui os mesmos ganhos em conhecimento que uma pessoa que completa o ensino superior, haja vista a diferença de complexidade dos temas e conteúdos abordados em cada nível de educação. Portanto, a educação foi operacionalizada em quatro categorias dicotômicas da seguinte forma: (i) Até Ensino Médio Incompleto, (ii) Ensino Médio Completo, (iii) Ensino Superior Incompleto, (iv) Ensino Superior Completo ou Pós-graduação, utilizando como categoria base os indivíduos com até ensino médio incompleto.

Interesse: Interesse é a motivação de se buscar informação sobre algum objeto, neste estudo a informação política. Os dados de 2014 fornecem uma pergunta para relatar o próprio interesse do entrevistado na política. Na pergunta, o entrevistado tem oportunidade de relatar de muito interesse a nada interessado, sendo possível não saber ou não responder. A variável será operacionalizada de forma dicotômica, sendo muito interessado e interessado igual a 1 e pouco interessado e nada interessado igual a 0. Em 2010, essa mesma pergunta não estava incluída no questionário, assim utilizamos como pergunta proxy para o interesse, a pergunta sobre a proximidade do indivíduo do acompanhamento das eleições ${ }^{7}$.

Idade: Idade mede uma posição no ciclo de vida de um indivíduo (DELLI CARPINI e KEETER, 1996). O acúmulo de anos significa mais tempo de exposição às informações políticas, sociais e econômicas, como também significa motivação em se buscar informações. Por exemplo, um adulto possui maior interesse em política do que um adolescente, pois assuntos como impostos, burocracia e eleições, comuns do mundo político, fazem parte do

\footnotetext{
7“COMO O(A) SR(A) ACOMPANHOU A CAMPANHA ELEITORAL? DE FORMA: Muito próxima; Próxima; Distante; Muito Distante". Codificamos de forma semelhante ao ESEB 2014 (binária), sendo "muito próxima; próxima" igual a e "distante; muito distante" igual a zero.
} 
cotidiano de um adulto. Com relação aos mais idosos, será que esse interesse decai com a idade? Provavelmente não. Apesar de que a partir certa idade o brasileiro não ser mais obrigado a votar, outros assuntos como a previdência social e aposentadoria, predominantemente públicos, fazem com que os idosos ainda permaneçam motivados a buscar informação política. Nota-se que a experiência pode funcionar como algo que antecipe alguns acontecimentos ou o funcionamento de governos (DELLI CARPINI e KEETER, 1996), facilitando o entendimento do contexto e dos cenários.

Ocupação: Em Luskin (1990), a ocupação é operacionalizada no sentido de political impingement, ocupações que trabalham diretamente ou indiretamente com a esfera governamental. Dessa forma, possuem maior oportunidade de encontrar informação política. O principal exemplo é o serviço público, em que o crescimento e a profissionalização da burocracia estatal aumentaram a proporção dos trabalhadores em ocupações políticas. Sendo assim, espera-se dessas ocupações pessoas sejam mais sofisticadas para exercerem seus cargos do que profissões que não trabalham diretamente com o governo, pois estão expostas diariamente com decisões do governo e assuntos políticos. Logo, a ocupação é operacionalizada entre aqueles que possuem cargos "politizados" (1) e os que não possuem (0). Aquelas ocupações "politizadas" são os da administração pública, ONGs e atividades sociais, os demais ramos de atividade, como agricultura, comércio, indústria, apesar de serem influenciadas por ações governamentais, é uma influência indireta. Portanto, não são operacionalizados como ocupação "politizada".

Renda familiar: Além de serem bem educadas, as pessoas informadas também tendem a ter melhores empregos, portanto, salários mais elevados do que as pessoas mal informadas ${ }^{8}$. Pessoas ricas são mais prováveis do que as demais de adquirir informação econômica e política por meio de suas atividades diárias (ALTHAUS, 1996), pois estão em altos cargos e possuem mais acesso à informação. Logo, renda é um fator essencial de diferenciação, pois os pobres têm acesso limitado a fontes de informação, assim como o acesso às melhores escolas é limitado aos ricos. Então, é razoável supor que os pobres tenham níveis mais baixos de conhecimento político (RENNÓ, 2007) do que os ricos. Logo, utilizamos renda familiar para capturar também a influência dos familiares sobre o nível de conhecimento individual.

Gênero e raça: Estas duas variáveis dicotômicas vêm de uma discussão sobre oportunidade e sociedade. As barreiras sociais que historicamente excluíram mulheres e negros da política, não somente do sufrágio, como também as desencorajaram dos cargos políticos, criaram um gap e distorções no conhecimento político entre tais grupos sociais, deixando os homens brancos sempre mais bem informados politicamente (LUSKIN, 1990;

\footnotetext{
${ }^{8}$ Althaus (1996) utiliza renda como proxy para os níveis de conhecimento político, embora renda em surveys sofra de maior erro de mensuração do que o nível educacional.
} 
DELLI CARPINI e KEETER, 1996; BARABAS ET AL., 2014; RENNÓ, 2006). Porém, os incentivos educacionais e ocupacionais podem ter o efeito de minimizar essa distância informacional (LUSKIN, 1990), mas tal efeito deve ficar restrito entre os altamente sofisticados.

Exposição à mídia impressa e geral: A mídia exerce um papel de oportunidade informacional. Ela disponibiliza a informação aos consumidores, assim, eles podem utilizá-la segundo suas capacidades. Segundo Luskin (1990), a mídia impressa possui maior capacidade informativa do que as outras mídias em geral, que possuem o foco em entretenimento. De qualquer forma, espera-se que a mídia, tanto impressa e geral, possua o papel de dar uma maior quantidade de informação aos indivíduos como também ser um fator de motivação, porque a leitura de jornal exige maior interesse e, assim aumente a quantidade de conhecimento político.

\section{Resultados}

O gráfico 1 abaixo apresenta a distribuição dos níveis de conhecimento político (variando de 0 a 7) entre os entrevistados no ESEB 2010. Os resultados mostram uma distribuição relativamente normal.

Gráfico 1: Distribuição da variável de conhecimento político do ESEB 2010.

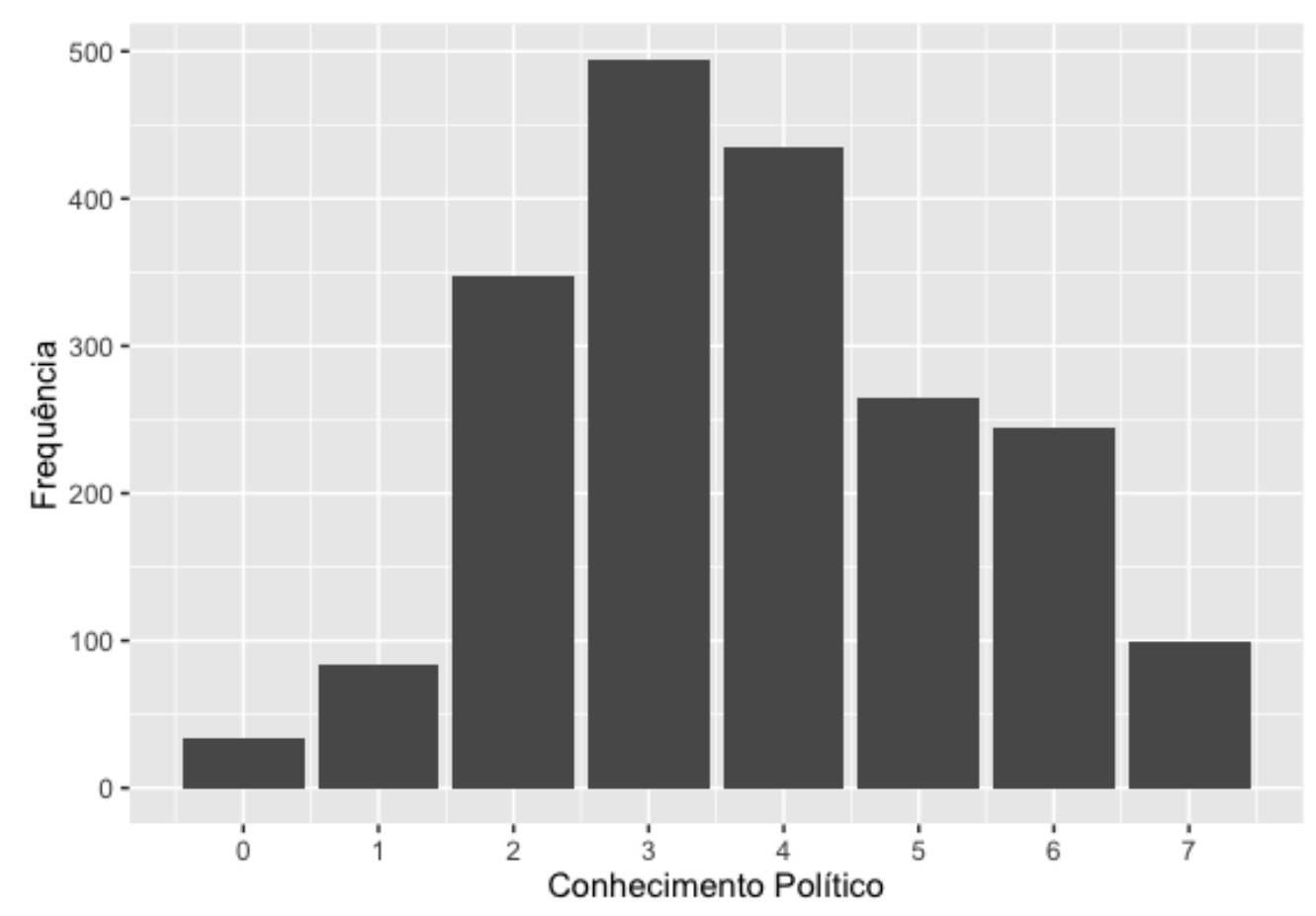

Fonte: elaboração própria dos autores.

Para os entrevistados no ESEB 2014 a distribuição dos níveis de conhecimento 
político (variando de 0 a 7) está no Gráfico 2, o qual mostra o que décadas de pesquisa, no Brasil e em outros países, sempre indicaram, os cidadãos sabem pouco sobre política (DELLI KARPINI e KEETER, 1996; RENNÓ, 2007). A distribuição é fortemente assimétrica à direta e os entrevistados estão concentrados nos níveis mais baixos de informação $(0,1$ e 2).

A diferença nos níveis de conhecimento político entre 2010 e 2014, com níveis maiores de conhecimento político no primeiro, deve-se a diferença dos itens utilizados na escala de conhecimento de cada ano. Devido à diferença na composição das escalas de conhecimento político e não a uma variação ao longo do tempo, o pressuposto de "dificuldade igual dos itens" não é cumprido, logo, tais resultados no nível geral de conhecimento da população são encontrados. Em Barabas e colegas (2014), evidencia-se que o uso de diferentes tipos de perguntas para a construção da escala de conhecimento político não é intercambiável. Na escala de 2014 são utilizados itens mais específicos de políticas e menos de conhecimento factual, o que demanda dos entrevistados maior motivação para a aquisição desse tipo de informação afetando os resultados da escala.

Gráfico 2: Distribuição da variável de conhecimento político do ESEB 2014.

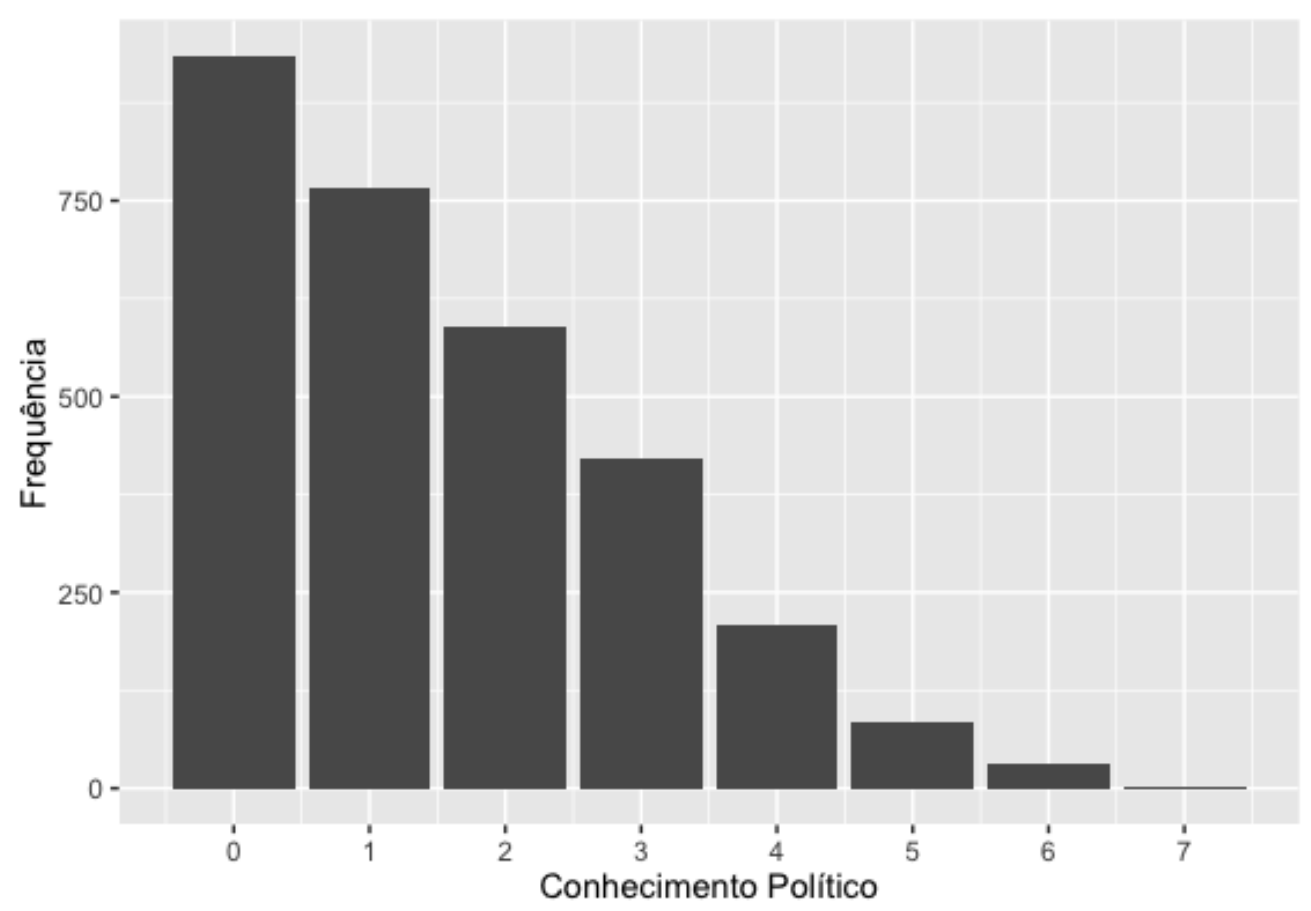

Fonte: elaboração própria dos autores.

O desmembramento das 7 (sete) perguntas que compõem a variável de conhecimento político nas Tabela 1 e 2 mostram que a informação aumenta com o nível educacional do respondente, o que pode ser visto pela maior porcentagem de itens respondidos corretamente nos estratos mais altos de educação em comparação com o nível mais baixo.

O primeiro item questiona se Geraldo Alckmin é filiado ao PTB e o nível de acerto 
aumenta de acordo com o grau de escolaridade do respondente. Para o segundo item sobre a duração do mandato presidencial, todos os níveis escolares possuem uma taxa alta de acerto (sempre acima de $90 \%$ dos entrevistados), assim como o quarto item sobre a filiação de Lula quando eleito. A alta taxa de acerto para esses dois itens não é surpresa, uma vez que desde a constituição de 1988, o mandato para presidente foi estabelecido em 4 anos, e 2010 foi o fim de 8 anos de governo Lula.

Tabela 1: Taxa de respostas corretas de conhecimento político pela educação em 2010 (em \%).

\begin{tabular}{|c|c|c|c|c|}
\hline Item Questionário & $\begin{array}{l}\text { Até ensino } \\
\text { médio } \\
\text { incompleto } \\
(\mathrm{n}=1263)\end{array}$ & $\begin{array}{l}\text { Ensino } \\
\text { Médio } \\
(n=483)\end{array}$ & $\begin{array}{c}\text { Ensino } \\
\text { Superior } \\
\text { incompleto } \\
(\mathrm{n}=129) \\
\end{array}$ & $\begin{array}{l}\text { Ensino } \\
\text { Superior } \\
(n=125)\end{array}$ \\
\hline Filiação de Alckmin ao PTB & 25.57 & 38.92 & 54.26 & 54.4 \\
\hline Mandato presidencial de 4 anos & 91.7 & 95.8 & 98.4 & 95.2 \\
\hline $\begin{array}{c}\text { Voto majoritário para a Câmara dos } \\
\text { Deputados }\end{array}$ & 11.9 & 17.9 & 21.2 & 31.2 \\
\hline $\begin{array}{c}\text { Filiação de Lula quando eleito } \\
\text { presidente }\end{array}$ & 91.4 & 97.1 & 98.4 & 99.2 \\
\hline Ideologia individual & 48.3 & 60.1 & 73.6 & 87.2 \\
\hline $\begin{array}{l}\text { Posicionamento ideológico: } \\
\text { PT ao PSDB }\end{array}$ & 22.5 & 32.3 & 45.7 & 56.0 \\
\hline $\begin{array}{l}\text { Posicionamento ideológico: } \\
\text { PT ao DEM }\end{array}$ & 14.5 & 21.7 & 35.6 & 46.4 \\
\hline
\end{tabular}

Fonte: elaboração própria dos autores.

O terceiro item versa sobre o tipo de voto para a Câmara Federal dos Deputados, nessa pergunta percebemos um padrão de diferença entre respondentes com alta e baixa escolaridade, com cerca de $20 \%$ a mais de respostas corretas para os cidadãos de alta escolaridade. Os últimos três itens da escala envolvem a noção mais complexa de ideologia. Aqui um padrão se revela: os indivíduos com educação superior possuem as maiores taxas de acerto das posições ideológicas partidárias e declaram uma ideologia. 
Tabela 2: Taxa de respostas corretas de conhecimento político pela educação em 2014 (em \%).

\begin{tabular}{|c|c|c|c|c|}
\hline Item Questionário & $\begin{array}{l}\text { Até ensino } \\
\text { médio } \\
\text { incompleto } \\
(\mathrm{n}=1.720)\end{array}$ & $\begin{array}{l}\text { Ensino } \\
\text { Médio } \\
(\mathrm{n}=861)\end{array}$ & $\begin{array}{c}\text { Ensino } \\
\text { Superior } \\
\text { incompleto } \\
(\mathrm{n}=263)\end{array}$ & $\begin{array}{l}\text { Ensino } \\
\text { Superior } \\
(n=292)\end{array}$ \\
\hline $\begin{array}{c}\text { Ministro da Fazenda no primeiro } \\
\text { mandato de Dilma }\end{array}$ & 23.7 & 40.8 & 47.9 & 65.1 \\
\hline $\begin{array}{c}\text { Taxa de desemprego no Brasil } \\
\text { em agosto de } 2014\end{array}$ & 10.9 & 12.2 & 22.8 & 26.4 \\
\hline $\begin{array}{l}\text { Segundo maior partido na } \\
\text { Câmara dos Deputados }\end{array}$ & 18.2 & 19.9 & 22.4 & 24.0 \\
\hline Atual Secretário Geral da ONU & 6.5 & 9.9 & 10.3 & 19.5 \\
\hline Ideologia individual & 41.9 & 45.4 & 53.7 & 63.3 \\
\hline $\begin{array}{c}\text { Posicionamento ideológico: } \\
\text { PT ao PSDB }\end{array}$ & 14.3 & 17.5 & 22.8 & 34.2 \\
\hline $\begin{array}{c}\text { Posicionamento ideológico: } \\
\text { PT ao DEM }\end{array}$ & 9.2 & 11.8 & 20.5 & 25.7 \\
\hline
\end{tabular}

Fonte: elaboração própria dos autores.

O primeiro item questiona sobre o ministro da fazenda do primeiro mandato de Dilma Rousseff e apresenta o maior número de acerto dos portadores de diploma superior das perguntas factuais. Os três itens seguintes, que também envolvem perguntas factuais sobre política apresentam as menores diferenças entre os entrevistados. Mesmo os respondentes com alta escolaridade possuem baixas taxas de acerto.

Os últimos três itens da escala envolvem as noções de ideologia. Nessas perguntas, percebemos o mesmo padrão de diferença entre respondentes com alta e baixa escolaridade de 2010, a taxa de acerto cresce com o aumento da escolaridade. Entretanto, esses primeiros resultados são apenas descritivos, os quais não são suficientes para testarmos a hipótese (H2) sobre o efeito não linear da escolaridade e do ensino superior como basilar do conhecimento político.

A Tabela 3 apresenta o modelo de regressão ${ }^{9}$ utilizado para os determinantes do conhecimento político nos anos de 2010 e 2014. No modelo linear, os coeficientes do modelo indicam o aumento de valor em y de acordo com o aumento de uma unidade em x, assim, pode-se ver a magnitude do efeito de cada variável incluída no modelo enquanto os demais fatores são mantidos constantes. O modelo tem bom ajuste, um $\mathrm{R}^{2}$ de .17 e .18, respectivamente, os erros-padrão são baixos, o que mostra que não existe multicolineariedade

\footnotetext{
${ }^{9}$ Ainda que yi não sejam provenientes de uma distribuição normal, podemos usar o teorema do limite central (havendo graus de liberdade grandes suficiente) para concluir que os estimadores satisfazem a normalidade assintótica, o que significa que eles são, de maneira aproximada, normalmente distribuídos em amostras de tamanhos suficientes grandes. O pressuposto da normalidade não tem nenhum papel na inexistência de viés de MQO, tampouco afeta o fato que o MQO é o melhor estimador linear não-viesado sob as hipóteses de GaussMarkov (WOOLDRIDGE, 2011). Do ponto de vista teórico, existe uma regularidade, uma vez que os resultados do modelo em 2014 seguem o mesmo padrão do modelo de 2010, que tem uma distribuição normal.
} 
entre as variáveis independentes e que as variáveis se comportam como esperado teoricamente.

A medida de conhecimento político foi categorizada também ordinalmente e realizadas regressões ordinais para três categorias ordenadas de conhecimento: baixo, médio e alto. O modelo de regressão ordinal em vez de considerar a probabilidade de um evento individual, calcula a probabilidade desse evento e todos os eventos que são ordenados antes dele, resumindo as relações entre as variáveis explicativas e o resultado em um único modelo parcimonioso.

Tabela 3: Regressão Linear para os determinantes do Conhecimento Político do eleitorado brasileiro em 2010 e 2014.

$2010 \quad 2014$

\begin{tabular}{|c|c|c|c|c|}
\hline & Estimativa & Erro padrão & Estimativa & Erro padrão \\
\hline Constante & $2.35 * * *$ & .23 & $1.33 * * *$ & .13 \\
\hline Ensino Médio Completo & .20 & .19 & $.19 * *$ & .07 \\
\hline Ensino Superior Incompleto & $.44 * *$ & 0.28 & $.58 * * *$ & .11 \\
\hline Ensino Superior Completo & $.50 *$ & .25 & $.95 * * *$ & .11 \\
\hline Gênero (mulher) & $-.36^{*}$ & .17 & $-.37 * * *$ & .05 \\
\hline Raça (negro) & $-.17 * * *$ & .25 & $-.29 * * *$ & .06 \\
\hline Exposição à mídia impressa & $.44 * * *$ & .24 & $.39 * * *$ & .06 \\
\hline Ocupação & .32 & .20 & $.22 *$ & .10 \\
\hline \multicolumn{5}{|l|}{ (politcal impingement) } \\
\hline Interesse & $.37 * * *$ & .16 & $.63 * * *$ & .06 \\
\hline Idade & .12 & .07 & .02 & .01 \\
\hline \multirow[t]{2}{*}{ Renda Familiar } & $.28 * * *$ & .07 & $.17 * * *$ & .04 \\
\hline & $\begin{array}{c}N \\
718\end{array}$ & $\begin{array}{l}R^{2} \\
.17\end{array}$ & $\begin{array}{c}N \\
2595\end{array}$ & $\begin{array}{l}R^{2} \\
.18\end{array}$ \\
\hline
\end{tabular}


A Tabela 4 reporta as probabilidades preditas para cada nível educacional, utilizando como categoria base os indivíduos com até ensino médio incompleto. Os valores em negrito na tabela indicam a categoria de conhecimento político com maior probabilidade de um indivíduo de determinado nível educacional pertencer.

Tabela 4: Regressão Logística Ordinal para o Conhecimento Político do eleitorado brasileiro em 2010 e 2014 (probabilidades preditas).

\begin{tabular}{|c|c|c|c|c|c|c|c|c|}
\hline & \multicolumn{3}{|c|}{2010} & \multicolumn{5}{|c|}{2014} \\
\hline & $\begin{array}{l}\text { Ensino } \\
\text { Médio }\end{array}$ & $\begin{array}{c}\text { Ensino } \\
\text { Superior } \\
\text { Incompleto }\end{array}$ & $\begin{array}{l}\text { Ensino } \\
\text { Superior }\end{array}$ & $n$ & $\begin{array}{l}\text { Ensino } \\
\text { Médio }\end{array}$ & $\begin{array}{c}\text { Ensino } \\
\text { Superior } \\
\text { Incompleto }\end{array}$ & $\begin{array}{l}\text { Ensino } \\
\text { Superior }\end{array}$ & $n$ \\
\hline $\begin{array}{c}\text { Baixo } \\
\text { conhecimento } \\
\text { político }\end{array}$ & .178 & .098 & .068 & 463 & .519 & .408 & .267 & 1699 \\
\hline $\begin{array}{c}\text { Médio } \\
\text { conhecimento } \\
\text { político }\end{array}$ & .469 & .381 & .314 & 929 & .366 & .425 & .458 & 1009 \\
\hline $\begin{array}{c}\text { Alto } \\
\text { conhecimento } \\
\text { político }\end{array}$ & .352 & .519 & .617 & 608 & .113 & .166 & .274 & 326 \\
\hline
\end{tabular}

Fonte: elaboração própria dos autores. '***' 0.001 '**' 0.01 '*' 0.05

\section{Discussão}

A educação formal é uma facilitadora da sofisticação política que tem relevância em todos os componentes da tríade oportunidade-motivação-habilidade: promove a habilidade cognitiva para a organização e o armazenamento das informações políticas, expõe a uma diversidade de informações e contextos sociais e motiva os estudantes a buscar o entendimento sobre o mundo político e social. Entre os graus de escolaridade, o ensino superior é o grande divisor de águas, pois expõe a contextos mais complexos e aguça o senso crítico dos estudantes.

A partir da Tabela 1 e 2, podemos observar que o acréscimo de cada grau de escolaridade gera um maior número de respostas corretas de conhecimento político. Cada grau a mais de escolaridade permite a acumulação, o acesso e a organização da informação necessária para responder corretamente as questões. Por exemplo, perguntas sobre regras eleitorais tal como o voto majoritário para a Câmara dos Deputados (em 2010) são exigidas estruturas cognitivas mais desenvolvidas, o que explica a maior taxa de acerto dos respondentes com ensino superior.

O item sobre a filiação de Alckmin mostra os respondentes de ensino superior com a maior taxa de acerto, enquanto o item da filiação de Lula uma alta taxa de acerto geral. Três 
motivos podem estar por de trás da grande diferença entre os dois itens: (i) o item exige acesso à memória de longo-prazo, uma vez que Lula e Alckmin disputaram o segundo turno presidencial de 2006, quatro anos antes; (ii) Lula foi eleito duas vezes presidente do Brasil e sempre filiado ao Partido dos Trabalhadores; (iii) as diferenças entre as duas perguntas revela um aspecto canônico na literatura de survey e opinião pública: o formato da pergunta influencia as respostas (TOURANGEAU et al., 2000). Para Lula pergunta-se se ele pertence ao próprio partido, o que facilita a associação do respondente, ao mesmo tempo que, para Alckmin pergunta-se se ele pertence a um outro partido (PTB), o que gera incertezas no momento de confirmação de associação do respondente, pois além de saber que o item é errado, ainda é necessário saber qual o partido correto de Alckmin.

A pergunta sobre o mandato presidencial de 4 anos apresenta uma alta taxa de acerto entre todos os níveis de escolaridade e reflete uma característica do sistema político brasileiro: o voto obrigatório. Votar é participar da política e participação direta tem uma função educacional. Ao forçar as pessoas participarem do processo eleitoral, o tema político torna-se ativo, o cidadão é obrigado a separar parte do seu tempo para processo votar e assim se aproximando da política.

Em questões como a do Ministro da Fazenda do primeiro mandato de Dilma (em 2014) é exigido acesso à memória de longo-prazo, que no caso dos indivíduos mais sofisticados, a recuperação de tal informação é mais eficiente através de um processamento de informação do tipo online ${ }^{10}$ (LAU e REDLAWSKI, 2006), o que faz sentido que seja uma pergunta com a grande taxa de acerto entre os respondentes com ensino superior.

Todavia, a segunda pergunta, sobre a taxa de desemprego em 2014, possui um cunho mais específico do que a primeira, o que demanda maior capacidade de recuperação da informação e motivação, consequentemente, mais sofisticação do respondente. As taxas de acerto são menores até mesmo dos maiores níveis de escolaridade, mas há um importante salto na quantidade de acerto quando passa para o nível de curso superior incompleto, o que nos leva a crer numa maior sofisticação desse nível adiante.

Da mesma forma, a pergunta sobre o Secretário da ONU se caracteriza por um domínio específico, política de relações exteriores. Essa pergunta exige uma grande motivação para aquisição de informação do que simplesmente habilidade adquirida pela educação (BARABAS ET. AL., 2014). Nós argumentamos que essa baixa taxa de acerto, até

\footnotetext{
${ }^{10} \mathrm{O}$ processamento online caracteriza-se pelo eleitor conhecer um candidato e acrescentar cada "pedaço" de informação ao longo do tempo em uma espécie de sumário ou registro, que é acessado no dia da escolha. As atitudes são formadas em tempo real (KIM; GARRETT, 2011), no momento que a exposição da informação ocorre, atualizando os registros. Então, o processo on-line é caracterizado pela construção da decisão ser realizada no momento da exposição da informação.
} 
dos mais escolarizados, deve-se ao fato do eleitorado brasileiro, ao contrário do americano ${ }^{11}$, por exemplo, não ter tanto interesse em política internacional, já que o Brasil não figura como potência mundial, como outras nações, principalmente os EUA. Logo, era esperado que o conhecimento político dos brasileiros em relação às políticas internacionais seja menor do que as demais perguntas de características institucionais e internas, levando a uma alta proporção de respostas de não sei/não respondeu. Ainda assim, a taxa de acerto dos indivíduos graduados chega quase ao dobro dos indivíduos que não completaram o ensino superior.

Esse resultado nos levar a questionar a presença dessa pergunta no questionário do ESEB de 2014. Primeiramente, qual tipo de informação factual um indivíduo deve saber para o bom exercício de seu dever cívico político. Segundo, se relações exteriores seria um domínio político fundamental, isto é, possuir conhecimentos sobre esse domínio é substancial para os indivíduos entenderem o fenômeno da política brasileira. Alguns eleitores podem ser generalistas, saberem um pouco sobre várias questões políticas distintas. Outros podem ter maior conhecimento de temas específicos, serem especialistas em certas áreas (RENNÓ, 2007). Um indivíduo é capaz de votar bem - de acordo com suas preferências - sem saber quem é o atual Secretário Geral da ONU, os impactos da política em nível global são mínimos no cotidiano político de um indivíduo.

As perguntas sobre ideologia apresentaram um comportamento interessante para ambos os anos do ESEB. Em Highton (2009), o efeito apresentado em cursar um ensino superior é no entendimento da ideologia. Na tabela, as perguntas de posicionamento da ideologia possuem um salto no número de acerto quando o indivíduo passa do ensino médio para o superior (completo ou incompleto), afinal, ela é uma forma de cognição política complexa. Esse salto não apresenta a mesma proporção quando vemos o número de acerto em perguntas factuais. Devido ao ambiente universitário e os debates políticos em seu âmbito, o entendimento ideológico é mais claro quando o entrevistado ao menos chega ao ensino superior.

A partidos modelos de regressão múltipla com os determinantes do conhecimento político, o interesse por política aparece como uma variável importante do modelo, com um coeficiente de .46 (2010) e .64 (2014). Entretanto, o tamanho do seu efeito deve ser ponderado. A construção da pergunta no questionário, perguntando ao entrevistado sobre o seu próprio interesse em política, pode ser alvo do chamado efeito de desejabilidade social (BERINSKY, 1999). Afirmar desinteresse em política não parece muito bem visto socialmente e até mesmo pelo próprio indivíduo, já que isso o afastaria da imagem de deveres de um bom papel cívico individual e ao pertencimento de uma sociedade democrática.

\footnotetext{
${ }^{11}$ Por exemplo, na disputa presidencial americana de 2008, em que o tema central foi acerca da Guerra do Iraque e a retirada de tropas, dividindo ainda mais o eleitorado.
} 
Tanto as variáveis gênero quanto raça possuem o sinal negativo, como esperado. A distribuição desigual de conhecimento político beneficia homens brancos de renda alta deixando-os mais bem informados, já que historicamente mulheres e negros foram politicamente excluídos e assim tiveram menos oportunidades de ter acesso à informação política (RENNÓ, 2007). As barreiras sociais (fatores sistêmicos) que historicamente excluíram mulheres e negros da política, não somente do sufrágio, como também as desencorajaram dos cargos políticos e da participação política, criaram um gap e distorções no conhecimento político entre tais grupos sociais, deixando os homens brancos sempre mais bem informados politicamente (LUSKIN, 1990; DELLI CARPINI e KEETER, 1996; BARABAS ET AL., 2014; RENNÓ, 2007). Esse cenário tende a explicar o sinal negativo das estimativas para gênero e a distribuição desigual de conhecimento político.

Exposição à mídia impressa inclui os efeitos tanto de oportunidade como de motivação. Envolve oportunidade, pois é necessário estar exposto e prestar atenção a informação para ser capaz de armazenar e processá-la, e motivação porque a leitura de jornais exige maior interesse individual. A maioria das pessoas utilizam as mídias de massa (televisão) para entretenimento e não informação, enquanto mídia impressa (jornais e revistas) são o "carro chefe" da informação armazenada (LUSKIN, 1990). Nossos resultados apontam para isso. Exposição à mídia impressa contribui para o aumento do conhecimento político, apesar de que como a variável interesse, as perguntas sobre uso de mídia possam sofrer tanto de desejabilidade social, entre os mais sofisticados, como de erros de mensuração, pois as pessoas podem não lembrar ou não ter certeza do verdadeiro uso pessoal.

A variável idade é a única que não possui coeficientes significativos em ambos modelos, assim como em Delli Carpini e Keeter (1996). A idade representa tanto uma posição no ciclo da vida, em que se espera que o acúmulo de conhecimento e a crescente sofisticação política do indivíduo com o passar dos anos, porém também reflete características de uma geração. Assim, características geracionais, como baixo engajamento político, podem pressionar e restringir o efeito positivo da variável idade, diminuindo o efeito da mesma no conhecimento político do eleitorado brasileiro. Mais pesquisas são necessárias para verificar quais as características de determinadas gerações no Brasil podem estar influenciando esse resultado.

A ocupação (political impingement) de um indivíduo também afeta a sofisticação política (.32 e .22, p<.05). Os ocupantes de cargos que necessitam saber o que os governos estão fazendo (funcionários públicos, membros de ONGs) ou devem fazer são mais expostos à informação política no dia-a-dia do que aqueles que possuem apenas uma relação indireta com decisões governamentais. 
Renda familiar teve seus efeitos reduzidos no modelo construído, o que não era esperado. Pessoas ricas são mais prováveis em adquirir informações econômica e política por meio de suas atividades diárias do que as demais (ALTHAUS, 1996). Igualmente, renda também tende mais a dividir temas econômicos entre os cidadãos, como papel e intervenção do estado, impostos e tributação (ALTHAUS, 1996). Porém, seus coeficientes (.28 e .17) não indicam grande influência nos resultados em comparação com os demais estimadores.

Fica claro que o ensino superior é a variável com maior coeficiente do modelo $(.50 \mathrm{e}$ .95). Esse resultado apresenta evidências favoráveis a nossa hipótese de que a educação superior é um forte preditor do conhecimento político (H1), pois seu coeficiente é alto, significante e, principalmente, positivo. Assim, completar o ensino superior é um divisor de águas, o indivíduo desenvolve habilidades cognitivas, recebe mais informação sobre a política e sente-se motivado a aprender mais.

Os demais graus de escolaridade apresentam os coeficientes positivos como esperado, porém os resultados demonstram que os ganhos de conhecimento político pela educação não podem ser tratados como uma variável linear nos modelos de sofisticação (H2). A linearidade da variável é concebida quando o ganho entre as suas categorias é homogêneo, o que não pôde ser observada com os resultados dos diferentes graus de escolaridade. Os resultados indicam que a complexidade, tanto dos conteúdos quanto do contexto social do ensino superior apontam para diferentes ganhos marginais de informação política - em quantidade e qualidade - e da importância desse nível escolar em específico para o aumento da sofisticação política do eleitorado e suas consequências para a democracia.

Os resultados para o modelo ordinal reforçam os resultados do modelo linear, indivíduos com ensino superior completo ou mais sempre apresentam as maiores probabilidades de pertencer a categoria de alto conhecimento político e as menores de pertencer a categoria de baixo conhecimento político, por exemplo, em 2010, um indivíduo com ensino superior completo tem $52 \%$ a mais de probabilidade de possuir alto conhecimento político do que um indivíduo com ensino médio incompleto, essa probabilidade aumenta para $62 \%$ quando o ensino superior é concluído.

Para 2010, indivíduos com ensino médio têm maior probabilidade de estarem na categoria média de conhecimento político, enquanto indivíduos com ensino superior (completo ou incompleto) têm maior probabilidade de estarem entre os indivíduos de alto conhecimento político. Em 2014, o mesmo padrão se repete, porém, para um nível geral de conhecimento abaixo. Tais resultados são devidos à distribuição assimétrica do conhecimento político de 2014, havendo poucos indivíduos na categoria mais alta, reduzindo as probabilidades. 


\section{Considerações finais}

Este estudo buscou explicar o papel da educação formal na sofisticação política, por meio de uma análise de regressão linear múltipla, a partir de dados obtidos no Estudo Eleitoral Brasileiro (ESEB) de 2014 e 2010. Os resultados apresentados mostram que o ensino superior, especificamente, possui o papel mais importante no conhecimento do eleitorado brasileiro (H1), uma vez que, além de ser o grau mais complexo em conteúdo, também expõe os estudantes a um contexto social mais diverso e estimula os indivíduos a procurar mais informações e serem mais críticos a elas.

Mesmo com escalas diferentes de conhecimento político nos dois anos estudados, o ensino superior ainda surge como primordial na determinação do nível de conhecimento político dos indivíduos. Portanto, não se pode tratar a educação formal como uma variável linear (H2), pois os seus diversos graus contribuem de forma diferenciada para a sofisticação política do eleitor. Assim, educação deve ser incluída nos modelos em suas devidas categorias dicotômicas.

A habilidade se encaixa na capacidade cognitiva e está fortemente relacionada com o nível de educação de um indivíduo. Como também, maior conhecimento político depende das oportunidades que se apresentam às pessoas, sendo elas condicionadas por questões atitudinais e estruturais. No Brasil e no mundo os detentores de altos níveis de sofisticação política ainda são indivíduos brancos, do sexo masculino, com alto grau de escolaridade e renda, em posições profissionais de maior prestígio, e com mais acesso e interesse pelas informações políticas veiculadas nos jornais e canais de televisão.

Educação tende a aumentar a consciência política e o apoio às instituições democráticas e nos últimos anos no Brasil, houve uma grande expansão do ensino superior, entretanto, educação não é o único determinante para evolução do conhecimento político de um país. Como vimos aqui, o interesse (motivação) é um fator importante também, apesar de sua operacionalização complexa. Fatores individuais como gênero, raça e renda também influenciam de forma decisiva como as pessoas compreendem e se comportam politicamente. Informação política obtida através da mídia impressa e geral também é importante para a opinião pública de todas as formas.

O estudo sobre a sofisticação e seus determinantes, portanto, nos leva a uma reflexão sobre a qualidade democrática que se tem no País. Os níveis baixos de conhecimento do eleitorado nos levam a questionar se as representações políticas são boas traduções das preferências da população. Com essa preocupação, o papel da educação é um debate relevante para que se possa capacitar, motivar e gerar oportunidades de se aprender sobre a política. Portanto, precisamos de teorização e de trabalhos empíricos sistemáticos que estabeleçam 
conexões entre o sistema de crenças, por um lado, e as decisões, julgamentos e atitudes dos cidadãos, por outro. 


\section{Referências}

ALTHAUS, S. L. "Opinion Polls, Information Effects and Political Equality: Exploring Ideological Biases in Collective Opinion". Political Communication, 13(1): 3-21. 1996.

. "Information Effects in Collective Preferences". American Political Science Review, v.92, p. 545-558. 1998.

BARABAS, J.; Et al, C. "The question(s) of political knowledge". American Political Science Review, v. 108 (4), p. 840 - 855. 2014.

BARTELS, L. M. "Uninformed Votes: Information Effects in Presidential Elections". American Journal of Political Science, v.40, p. 194-230. 1996.

BENNETT, S. E. "Democratic competence, before converse and after". Critical Review, 18:1-3, 105-141. 2006.

BERINSKY, A. J. “The Two Faces of Public Opinion”. American Journal of Political Science, v. 43, p. 1209-1230. 1999.

BULLOCK, J. G. "Companion to Re(:)measuring political sophistication". Political Science, 353. 2004.

CONVERSE, P. E. "The nature of belief systems in mass publics (1964)". Critical Review: A Journal of Politics and Society, 18:1-3, p. 1-74. 2006.

DELli C., M. X.; KEETER S. What Americans Know about Politics and Why it Matters. New Haven: Yale University Press. 1996.

DINESEN, P. T.; Et al. "Estimating the impact of education on political participation: evidence from monozygotic twins in the United States, Denmark and Sweden". Political Behavior, v. 38, p. 579 - 601. 2016.

ERIKSON, R. S.; TEDIN, K. L. American Public Opinion. 8th edition. New York: Pearson Longman. 2011.

HIGHTON, B. "Revisiting the Relationship between Educational Attainment and Political Sophistication”. The Journal of Politics, v. 71(4), p. 1564-1576. 2009.

KINDER, D. R. "Communication and opinion". Annual Review of Political Science. Vol. 1: 167-198. 1998.

"Belief systems today". Critical Review, 18:1-3, 197-216. 2006.

KIM, Y. M.; GARRETT, K. "Online and Memory-based: Revisiting the Relationship Between Candidate Evaluation Processing Models". Political Behavior 34: 345-368. 2011.

LAU R. R.; REDLAWSKI D. P. How voters decide: Information processing during election campaigns. New York: Cambridge University Press. 2006. 
D. J.; "An exploration of correct voting in recent U.S. presidential elections". American Journal of Political Science, v. 52, p. 395 - 411. 2008.

LUSKIN, R. C. "Explaining Political Sophistication”. Political Behavior, v.12, p. 33161. 1990.

NEUMAN, W. R. The Paradox of Mass Politics: Knowledge and Opinion on the American Electorate. Cambridge: Harvard University Press. 1986.

PRIOR, M.; LUPIA, A. "Money, Time, and Political Knowledge: Distinguishing Quick Recall and Political Learning Skills". American Journal of Political Science, v.52(1), p. 169-183. 2008.

RENNÓ, L. "Os militantes são mais informados? Desigualdade e informação política nas eleições de 2002”. Opinião Pública, v.12, p. 329-347. 2006.

"Desigualdade e informação política: as eleições brasileiras de 2002". Revista Dados, Rio de Janeiro, v. 50, p. 721-55. 2007.

TOURANGEAU, R., RIPS, L. J., RASINSKI, K. The psychology of survey response. Cambridge: Cambridge University Press. 2000.

WOOLDRIDGE, J. M. Introdução à Econometria: uma Abordagem Moderna. São Paulo: Cengage Learning, 2011.

ZALLER, J. R. The Nature and Origins of Mass Opinion. New York: Cambridge University Press. 1992. 